\title{
A Review on Ground Granulated Blast Slag (GGBS) in Concrete
}

\author{
Eskinder Desta Shumuye ${ }^{\mathrm{a}}$ and Zhao Jun ${ }^{\mathrm{b}}$
}

\begin{abstract}
Construction industry consumes a huge volume of concrete every year, and it is expected that it demand may increase soon. Concrete is one of the most widely used construction materials; main ingredient of concrete is cement. The demand for concrete as a construction material is on the increase. However, the production and utilization of cement causes pollution to the environment and reduction of raw material (limestone). The production of Portland cement worldwide is increasing annually. The current contribution of greenhouse gas emission from Portland cement production signifies the need for supplementary cementitious material as a supplementary pozzolanic material for concrete. This leads to the intensification of interest towards the utilization of wastes and industrial byproducts in order to minimize the Portland cement consumption. This paper reviews on the use of GGBS as a partial pozzolanic replacement of cement in concrete. The literature shows that GGBS was found to enhance the properties of concrete at later age subject to replacement level.
\end{abstract}

Key words: ASR, Concrete, Carbonation, Fracture and GGBS.

\section{Introduction}

Construction industry consumes a huge volume of concrete every year, and it is expected that it demand may increase soon[1]. Concrete is one of the most widely used construction materials; main ingredient of concrete is cement. The demand for concrete as a construction material is on the increase. It is estimated that the production of cement increased from about from 1.5 billion tons in 1995 to 3.2 billion tons in 2016[2].

However, the utilization of cement causes pollution to the environment and reduction of raw material (limestone). The production of Portland cement worldwide is increasing 9\% annually. The current contribution of greenhouse gas emission from Portland cement production is about 1.5 billion tons annually or about $7 \%$ of the total greenhouse gas emissions to the earth's atmosphere[2].

In general Ground slag has been used as a cementitious material in concrete since the beginning of the 1900s[3]. This paper focus on a review of various researched related to alternative partial cement replacement materials, specifically Ground Granulated Blast Slag (GGBS).

Eskinder Desta Shumuye ${ }^{\mathrm{a}}$ and Zhao Jun ${ }^{\mathrm{b}}$ School of Civil Engineering, Zhengzhou University ${ }^{(a, b)}$, Zhengzhou, China ${ }^{(a, b)}$

\section{Application of GGBS}

Blast furnace slag (BFS) and steel furnace slag (SFS) have a long history of use as industrial byproducts, going back almost 100 years in the United States and 150 years in Europe. Ground granulated blast furnace slag (GGBS) has been used in composite cements and as a cementitious component of concrete for many years. The first industrial commercial use (about 1859) was the production of bricks using unground granulated blast furnace slag (GBS). In the second half of the 19th century, its cementitious properties were discovered, and by the end of 19th century, the first cements containing GBS were produced. Since the late 1950 s, the use of GGBS as a separately ground material added at the concrete mixer together with Portland cement has gained acceptance. In some countries, the term 'slag cement' is used for pure GGBS[8].

Currently, GGBS were used as a direct replacement for Portland cement, on a one-to-one basis by weight. It is used to make durable concrete structures in combination with ordinary Portland cement and/or other pozzolanic materials. GGBS has been widely used in Europe, and increasingly in the United States and in Asia (particularly in China, India, Japan and Singapore) for its superiority in concrete durability, extending the lifespan of buildings from fifty years to a hundred years. In China, the application of GGBS is mainly as a clinker substitution in blended slag and normal cement production, and as a supplementary cementitious material in ready-mixed and site-batched concrete production[9]. At present, benefits derived from costs reduction is the direct and key driving force for the adoption of GGBS. GGBS used in the production of qualityimproved slag cement, namely Portland Blast Furnace Cement (PBFC) and High Slag Blast Furnace Cement (HSBFC) with GGBS content ranging typically from 30 to $70 \%$ and in the production of ready-mixed or site-batched durable concrete. GGBS reduces the risk of damages caused by alkali-silica reaction (ASR), provides higher resistance to chloride ingress reducing the risk of reinforcement corrosion and provides higher resistance to attacks by sulfate and other chemicals[10].

In addition, to the above-mentioned facts, unground GBS is suitable as a normal weight aggregate in concrete. It also used as a base layer material in road construction. Due to their low porosity, now a day, BFS aggregates are only used for asphalt road bases and sub-bases, but not for surface layers. One of the major benefits of using slag products in a stabilized pavement is the slow rate of the cementation process. The pavement material can be

reworked up to two days or more after initial mixing depending on the binder, without reducing the final strength. The performance of both GBS and GGBS in stabilization depends on the degree of fineness of the material, which in 
turn is a matter of economics. The cost of producing a finer grade of both GBS and GGBS, coupled with the reduced amount of slag stabilizing binder needed to provide equivalent strength, must balance against haulage costs[8]. The table below summarize the Manufacturing processes and applications for iron and steel slags.

\section{Effect of Ground Granulated Blast Slag in Concrete}

\section{A. Effects on Fresh Concrete}

This section provides a brief understanding of the effect of GGBS on freshly mixed concrete properties and its degree of influence. First it should be noted that effect of GGBS vary considerably depends on the degree of replacement on concrete mixtures.

\section{Setting Time}

Usually, an increase in time of setting expected when GGBF slag is used as a partial replacement for Portland cement in concrete mixtures. The degree to which the time of setting is affected is dependent on the initial temperature of the concrete, the proportion of the blend used, the watercementitious materials ratio, and the characteristics of the Portland cement[11]. The setting time of concrete with GGBS is generally greater than that of similar concrete with Portland cement. In general setting time increased with the increase in GGBS content[6]. "Peter W.C. Leung" also stated that, GGBS concrete requires longer setting times than Portland cement concrete, probably due to the smooth and glassy particle forms of GGBS. The setting time also increases with increasing percentage of GGBS replacements. The setting times of GGBS concrete are sensitive to low ambient temperatures[5].

Similarly, "S. Arivalagan" stated that the effect would be more pronounced at high levels of GGBS and/or low temperatures. An extended setting time is advantageous in that the concrete will remain workable for longer periods, therefore resulting in less joints. This is particularly useful in warm weather[12].

Wainwright and Ait-Aider (1995) investigated the effect of GGBS additions on the setting times and consistency of cements. Cement from three different sources and GGBS from one source were used. Cements were partially replaced with 40 and $70 \%$ of GGBS. They concluded that: (i) consistency and setting times results were almost similar for all sample sources of cements; (ii) inclusion of GGBS affected the consistency of cements, and it was reduced with the increase in GGBS content; and (iii) Setting time of cements was increased with the increase in GGBS content[6].

\section{Workability}

Fulton (1974) investigated workability in detail and suggested that a cementitious matrix containing slag cements exhibited greater workability due to the increased paste content and increased cohesiveness of the paste[7]. Wood (1981) reported that the workability and place ability of concrete containing GGBF slag yielded improved characteristics when compared with concrete not containing GGBF slag. He further stated that this result was due to the surface characteristics of the GGBF slag, which created smooth slip planes in the paste[11]. S. Arivalagan, investigated the workability factors of fresh concrete, by partially replacing cement with 20\%, 30\% and 40\% GGBS at different ages and he found that the degree of workability of concrete was normal, $26 \mathrm{~cm}, 27 \mathrm{~cm}$ and $28 \mathrm{~cm}$ respectively and it increased with the addition of GGBS[12].

"Quaid JoharBhattiwala" studied the relationship between workability and compressive strength of a concrete mortar. From his experimental result he conclude that when the workability of concrete increases the compressive strength of concrete decreases, but in case of $40 \%$ replacement of GGBS concrete it gets increases[13].

"Bahador Sabet Divsholi et. al." reported that increased slump and fluidity was measured with the increase in GGBS replacement percentage. For water-cementitious material ratio $(\mathrm{w} / \mathrm{c})=0.5$ and aggregate/cementitious material ratio $(\mathrm{a} / \mathrm{c})=3.0$, the slump was increased by $20 \%, 35 \%$ and $55 \%$ for $10 \%, 30 \%$ and $50 \%$ GGBS replacement, respectively[14].

"Sun-Woo Kim et. al." Investigate experimentally in his study the effect of GGBS on the workability of a concrete. The results compared to the control concrete, Ordinary Portland Cement concrete without GGBS. The result for the development of compressive result shows that concrete having GGBS resulted slower compressive development at early age. However, the strength development after 91 days shows a greater strength enhancement compared to the control mix[15].

"Asha Philips et. al." recommended the application of GGBS cement for structural purpose after conducting study on the mechanical property of geopolymer concrete using GGBS.

\section{B. Effect on Hardened Concrete}

This section provides a brief understanding of the effect of GGBS on hardenedd concrete properties and its degree of influence.

\section{Compressive Strength}

"S. Arivalagan" investigated the strength and strength efficiency factors of hardened concrete, by partially replacing cement with $20 \%, 30 \%$ and $40 \%$ GGBS at different ages. The specimens when tested at 7 and 28 days, showed in the table below increase in compressive strength for $20 \%$ replacement of cement. Split tensile strength and flexural strength of concrete also increased at $20 \%$ cement replacement[12].

Vinayak Awasare" studied, the strength characteristics of M20 grade concrete with a replacement of cement by GGBS with $30 \%, 40 \%$ and $50 \%$ and compare with the conventional concrete. At present artificial sand is used to replace natural sand, so study area extends to find the best percentage of replacement by using both crush and natural sand. The plain cement concrete prepared by OPC cement and crushed sand of M20 grade. The maximum compressive strength achieved is $29.78 \mathrm{Mpa}$ at $30 \%$ of GGBS replacement and those achieved for $20 \%, 40 \%$, and $50 \%$ of concrete is $27.11 \mathrm{Mpa}, 26.37 \mathrm{Mpa} \& 22.22 \mathrm{Mpa}$ respectively 
as compare to $25.61 \mathrm{Mpa}$ of strength of plain cement concrete for 28 days[16].

"B.Mangamma et.al." investigate the partial replacement of GGBS in a concrete production. He studied the compressive strength of a concrete by replacing GGBS in $10 \%, 20 \%, 30 \%, 40 \%$ and $50 \%$ of the binding material for M20 and M30. B.Mangamma, conclude that the partial replacement of GGBS increase the strengths at $10 \%, 20 \%, 30 \%$ as well as decrease the strength at $40 \%, 50 \%[17]$.

"Santosh Kumar Karri et. al." also selected 30\%, 40\% and $50 \%$ as cement replacement levels and cured the specimens of M20 and M40 grade of concrete for 28 and 90 days. He found out that the workability of concrete increases with the increase in GGBS replacement level. He observed that the maximum compressive strength, split tensile strength and flexural strength is achieved at $40 \%$ cement replacement for both M20 and M40 grade concrete, beyond which the strength decreases slightly.

According to "Maitri Mapa et.al." By increasing the curing days, the effect on strength reduction due to GGBS incorporation is decreasing. This may be due to the initial slow pozzolanic reaction for the GGBS replacement, which mainly depends on the availability of calcium hydroxide and silica. This reaction rate might have accelerated at the later ages and thus the strength gain process takes longer time for the GGBS mixed mortars. However, effect of replacement of GGBS in compressive strength test is not so distinct in CEM20GS mortar specimens for all days and for CEM40GS mortar specimens at 28 and 90-day of curing[18].

However, the negative effect of GGBS replacement on mechanical strength has been observed very noticeably for $60 \%$ and $80 \%$ replacement, for all days' compressive strength of cement mortar decreases severely at early ages with the increased replacement levels of GGBS in cement. In comparison with control, cement cubes, the strength decreases by $9.58 \%$ at 1 st day, $15.87 \%$ at 3rd day, $20.75 \%$ at 7 th day, $9.11 \%$ at 28 th day and only $4.08 \%$ at 90 th day for CEM20GS. Mortar cubes of CEM40GS shows that the strength decreases by $14.25 \%$ at 1 st day, $31.16 \%$ at $3 \mathrm{rd}$ day, $30.45 \%$ at 7 th day, $12.75 \%$ at 28 th day and $6.62 \%$ at 90 th day with respect to control cement mortar cubes. In case of CEM60GS mortar cubes, the strength decreases by $61.70 \%$, $64.96 \%, 64.03 \%, 43.59 \%$ and $28.11 \%$ at 1 st, 3rd, 7th, 28th and 90th day respectively of curing in comparison to control cement mortar cubes[18]. As the modulus of elasticity of concrete is related to its compressive strength, in general, the effect of GGBS increases slightly the elastic modulus of concrete for a given compressive strength when compared with the PC concrete.

\section{Fracture}

Fracture can be defined as the process of separation (or fragmentation) of a solid into two or more parts under the action of a stress. Cracks are present in all plain and reinforced concrete structures. Cracks often act as stress concentrators in many cases and they are the main reason for catastrophic crack propagation and structural failure under increasing load.

The characteristic length is often considered as material property, and it gives a measure of the brittleness of the material. Cement paste has a characteristic length in the range $5-15 \mathrm{~mm}$, mortar in the range $100-200 \mathrm{~mm}$, and concrete 200-400 mm. Compared to normal-strength concrete, high strength concretes and lightweight aggregate concrete have lower characteristic lengths. When the $(\mathrm{a} / \mathrm{d})$ ratio increases characteristic length decreases. It shows that the degree of brittleness is increases when the $(\mathrm{a} / \mathrm{d})$ ratio increases. It shows that when the crack starts propagates into the structure the degree of brittleness of the concrete starts increasing. From the experimental values of characteristic length from the test results of total of 27prisms, 6cubes, 18 cylinders with M30 grade geopolymer concrete and conventional concrete (OPC) of same grade. It is observed that for GPC oven cured specimens the difference in characteristic length from 0.1 to 0.15 and 0.1 to 0.2 are higher than the difference in characteristic length from 0.1 to 0.15 and 0.1 to 0.2 for other concrete. Since the characteristic length is inversely proportional to degree of brittleness, the OPC and GPC ambient cured specimens show more brittleness while crack propagation. Thus, it can be concluded that a crack present in structure pushes the structure to fail in brittle manner when the crack length approaches a particular value.

It is clear that the Characteristic length decreased with the notch depth ratio. A higher the Characteristic length indicates a ductile failure in a structure allowing more dissipation of energy. A smaller Characteristic length indicates a brittle failure. Thus with increase in the notch depth ratio (or) increase in crack length reduces the characteristic length, there by pushing a structure into a brittle state. According to the experimental result, GGBS oven cured concrete shows better structural performance in terms of fracture parameters like fracture toughness, characteristic length and critical stress intensity factor compared to geopolymer concrete cured at ambient conditions[19].

\section{Drying Shrinkage}

The creep of concrete is the deformation of hardened concrete caused by a long-lasting constant load applied on it. Creep, or plastic flow, is the increase in strain with time due to a sustained load. Initial deformation due to the load is an instantaneous strain, while the additional strain due to the same sustained load is the creep stain[20]. Drying shrinkage of concrete is the shrinkage caused by evaporation of internal water in hardened concrete. Creep and drying shrinkage are very important time-dependent properties of high-performance concrete (HPC).

This shrinkage causes an increase in tensile stress, which may lead to cracking, internal warping and external deflection. It influenced by a variety of factors, including environmental conditions (temperature, relative humidity and air circulation), size of the member (surface area to volume ratio), concrete material composition and structure, volume and elastic modulus of aggregate and water/binder ratio. The Impact of GGBS in drying shrinkage when the ambient temperature rise, GGBS has a little impact on drying shrinkage of concrete[21]. Most of the results available on drying shrinkage seem to indicate that the replacement of cement by GGBS has little or no influence on this property of concrete. A direct comparison of results from different investigators is sometimes difficult because of the differing conditions under which the tests were carried out. Further studies recommended on the impact of GGBS on drying shrinkage. 


\section{Permeability and Chemical Stability}

The presence of GGBS in concrete results in denser microstructure of the concrete matrix, which enhances the durability properties[12]. "Dongqing Zhang et.al." investigates the chloride permeability of concrete with slag or (20 wt. \%, $30 \mathrm{wt} \%$, and $40 \mathrm{wt} . \%$ of binder) and binary slag and fly ash (the ratio of slag and fly ash 5:5, 4:6 and $6: 4)$. The results show that the chloride ion permeability of concrete incorporating fly ash is lower than the control concrete (without mineral admixtures). Especially, when the content of fly ash is $20 \%$, the chloride permeability is very low. In general, fly ash admixed into concrete replacing a part of cement has two important roles: (1) potential pozzolanic reaction with calcium hydroxide; 2) microaggregate filling in the pores. In addition, test results of the chloride ion permeability of concrete using slag indicated that the chloride ion permeability decreases dramatically with the increment of the content of slag[22]

\section{Carbonation}

In addition to shrinkage upon drying, concrete undergoes carbonation shrinkage. Many experimental data include both types of shrinkage but their mechanism is different.

Carbonation of concrete is a process by which carbon dioxide from the air penetrates the concrete and reacts with the hydroxides, such as calcium hydroxide, to form carbonates. In the reaction with calcium hydroxide, calcium carbonate formed. Carbonation lowers the alkalinity of concrete. High alkalinity is needed to protect embedded steel from corrosion; consequently, concrete should be resistant to carbonation to help prevent steel corrosion[3].

Concrete carbonation is one of the most important phenomena affecting the durability of concrete. Concrete carbonation has been studied extensively over the last few decades. However, due to the time consuming process of carbonation, many researchers have used accelerated carbonation test to shorten the experimental time. Considering the complex process of carbonation and the number of parameters involved, there are always some uncertainties in the accelerated carbonation test results. Most importantly, the moisture content and moisture profile of the concrete before the carbonation test can significantly affect the test results[14]

"Bahador Sabet Divsholi et. al." Investigate the effect of carbonation on GGBS blended cement through by performing test for more than 200 samples with various water- cementitious materials ratio $(0.4,0.5$ and 0.6$)$ and various replacement percentages of GGBS. His carbonation test was carried out in the span of four years to study the natural carbonation rate of GGBS- blended concrete. $\mathrm{He}$ used Phenolphthalein indicator to freshly cut concrete surface and measure the carbonation depth. As we can see in the figure below the rate of carbonation for the samples with 30 and $50 \%$ GGBS replacement increased, however longer period of water curing for GGBS blended cement concrete reduced the carbonation rate and reduce the concern of increased carbonation rate. According to Bahador Sabet Divsholi et. al. The only drawback reported for the GGBS blended cement concrete is the increased rate of carbonation due to consumption of calcium hydroxide[14].

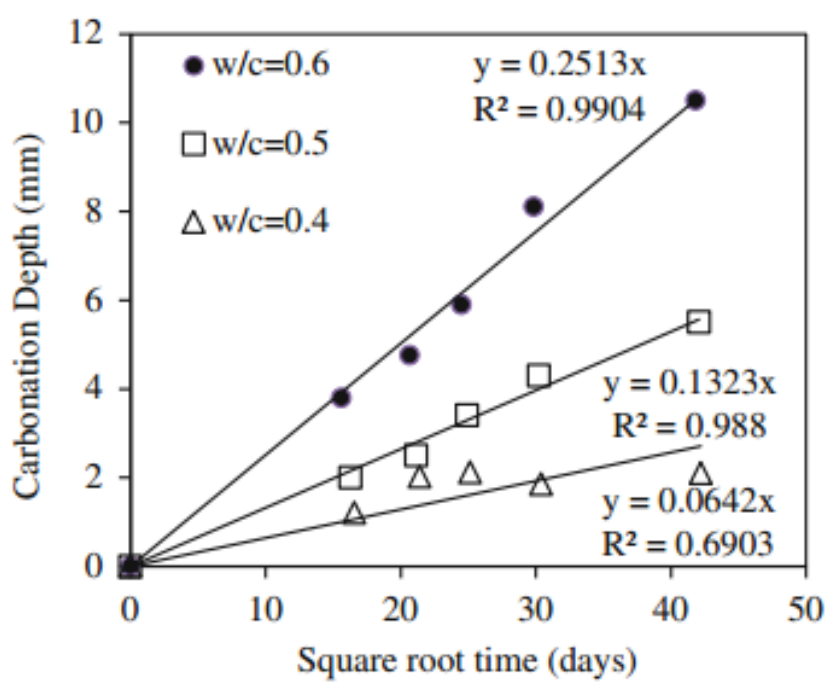

Figure 1:Effect of $w / c$ ratio (a/c $=4$ and 4 days curing) [14]

\section{Sulfate Resistance of Concrete}

Solution of sulfate can attack the hardened cement paste in the concrete causing deterioration. The precise chemical reaction will depend on the nature of the sulfate present and the type of cement. In some clay soils, the ground water is a solution of magnesium and calcium sulfates. These salts react with the $\mathrm{Ca}(\mathrm{OH})_{2}$ and the calcium aluminate hydrate in the concrete to produce gypsum and calcium sulphoaluminate. These products have considerably greater volume than the compounds they replace, leading to expansion and disruption of the concrete. The rate and extent of sulfate attack depends upon the ease with which sulfate ions are able to penetrate the concrete and upon the chemical resistance of the cement paste[23].

Where GGBF slag are used in sufficient quantities, several changes occur which improve resistance to sulfate attack. Those changes include: (1) The $\mathrm{C}_{3} \mathrm{~A}$ content of the mixture is proportionally reduced depending on the percentage of GGBF slag used. (2) Through the reduction of soluble calcium hydroxide in the formation of calcium silicate hydrates, the environment for the formation of calcium sulfo-aluminate is reduced. (3) Investigations indicate that resistance to sulfate attack is greatly dependent in the permeability of the concrete or cement paste. Again, the formation of calcium silicate hydrates in pore spaces, normally occupied by alkalies and calcium hydroxide, reduces the permeability of the paste and prevents the intrusion of the aggressive sulfates.[11].

\section{Alkali aggregate Reaction}

Alkali Silica Reaction (ASR) is a chemical reaction between alkalis in Portland cement and certain types of silica in aggregates. It results in the formation of expansive gels, which lead to cracking of the concrete. The cycle continues until the concrete is no longer serviceable. The presence of ASR will initially produce an expansion of the concrete that can be measured

GGBS could be very effective in controlling ASR because: (i) GGBS reduces the alkalinity of the concrete, and thus the alkali-silica ratio; (ii) GGBS reduces mobility of alkalis in the concrete; and (iii) GGBS reduces free lime in the concrete which is regarded as an important factor for 
alkali silica reaction[6]. On the other hand, supplementary, cementing materials that reduce alkali-silica reactions will not reduce alkali-carbonate reactions, a type of reaction involving cement alkalies and certain dolomitic limestone's[3].

"Ke-Liang LI et. al." studied the effect of mineral admixture to restrain ASR by doing experimental works on three kinds of mineral admixtures namely; fly ash, silica fume, and GGBS used with alkali contents of $0.53 \%$, $1.37 \%$, and $0.56 \%$ respectively together with OPC. Crushed quartz glass with an amorphous silica content of more than $90 \%$ was used as the reactive fine aggregate. Analyses have done on concentrations of hydroxyl, potassium and sodium ion in the pore solution. The water contents must be considered because they are different in different samples. Samples were calculated by mass loss through drying the samples at $105{ }^{\circ} \mathrm{C}$ for 24 hours[24]. The concentration of hydroxyl ions is critical in determining the degree of attack on the silica in aggregate. The available sodium and potassium in the pore solution determine the composition of the resulting gel and its capability to absorb water and cause expansion.

Mineral admixtures reduce concentrations of hydroxyl, potassium and sodium ion and expansions of mortar-bars due to ASR, so that they reduce damage from ASR. The results show that mineral admixtures used successfully to control the expansion due to ASR. The combined addition of different mineral admixtures is more effective than the addition of a single type of mineral admixture to control the expansion due to ASR. He conclude that, Mineral admixtures have effective restrain on ASR when they partially replace cement. When three kinds of mineral admixtures are used together, a compound effect to restrain ASR is obtained[24].

\section{Chloride Penetration}

The main cause of premature deterioration of reinforced concrete structures is the corrosion of steel bars, induced by chloride ions (for example in marine environment) and/or by carbonation (atmospheric $\mathrm{CO}_{2}$ ).

"Mickael Saillio et. al." investigate about the chloride ingress for concrete and cement pastes partially carbonated or/and in presence of sulphide in chloride contact solution. The mixtures contain OPC alone or with supplementary cementitious materials (SCM). SCMs are here pozzolanic materials (Fly Ash or Metakaolin) or alkali-activated materials such as ground granulated blast furnace slag (GGBS). The materials partially carbonated (2 months in chamber at $1.5 \%$ of $\mathrm{CO}_{2}$ ) or not, samples are put in contact with chloride solutions in presence of sulphide. Finally, he conclude that chloride ingress is accelerated by carbonation or/and the presence of sulphate in contact solution. This increase is explained by a change in the microstructure and the pore solution but also by a lower chloride binding. With regard to chloride ingress, there are differences between the various cementitious matrices. Cementitious matrixes with high metakaolin or slag content are more resistant to the effect of the presence of sulphate in the contact solution. Concrete having GGBS (62\%) seems to be the most resistant to the effect of carbonation and the presence of sulphate in contact solution on chloride ingress. However, he also mentioned about factor that affect the chloride ingress in a concrete, that the experimental conditions and pre-treatment (curing time, drying and relative humidity) also have an influence on the results of chloride ingress[25].

"H.H Seleem et.al." Studied that the performance of blended cement concrete against seawater attack. Concretes, tested for strength deterioration ratio (SDR) after 3, 6 and 12 month of exposure to synthetic seawater, permeability also measured after 6 and 12 months of exposure. The strength deterioration ratio (SDR) increases with age for all mixtures except for the mixture containing GGBS as the reduction in strength decreased from about $5.3 \%$ at 3 months to about $3.0 \%$ at 12 months, which appreciate GGBS as the most efficient in retaining strength in marine environment. In addition, according to his experimental result all kinds of pozzolanic materials are efficient in reducing the permeability of concrete far below the control one[26].

\section{Conclusions}

Based on the studies of diverse researchers on partial replacement of cement with GGBFS, some relevant conclusions are drawn which are as follows:-

- All kinds of pozzolanic materials are efficient in reducing the permeability of concrete far below the control one.

- Workability of concrete increases with the increase in GGBFS replacement level.

- As the GGBS content increases, the water/binder ratio also decreases for the same workability and thus, the GGBS has positive effects on the workability.

- In most of the cases, compressive strength decreases with the increase in percentage of GGBS at early age but it increases with increase in percentage of GGBS at later ages.

- Split tensile strength and flexural strength also decreases with the increase in percentage of GGBS at early age but it increases with increase in percentage of GGBS at later ages.

- The increase in strength is up to a certain limit of replacement, and after that, it starts decreasing and finally in later age the strength increases this is due to the slow speed of reaction between GGBS and $\mathrm{Ca}$ $(\mathrm{OH})_{2}$.

- Heat of hydration is slower in case of GGBS cement, which lowers the risk of shrinkage cracking, and make this cement more favorable in high temperature construction areas.

- Chloride and sulfate resistance of concrete increased as the percentage of GGBFS increased.

- GGBS fails the initial absorption confirming that the surfaces of their concrete mixes were practically impermeable.

- The replacement of cement by GGBS helps to reduce the cement content of concrete, thereby reducing the cost of construction because the price of GGBFS is about $25-50 \%$ less than that of OPC.

- Reuse of the slag helps to protect the environment from pollution (reduced $\mathrm{CO}_{2}$ emission) 
- Concrete having GGBS cement as a partial replacement resistant to the effect of carbonation and the presence of sulphide.

- The effect of GGBS increases slightly the elastic modulus of concrete for a given compressive strength when compared with the PC concrete.

\section{References}

[1] Balasubramanian Karthikeyan and Govindasamy Dhinakaran, "Effect of Grinding on Strength and Durability of GGBFS-based Concrete,' Jordan Journal of Civil Engineering, vol. 8, no. 4, p. 442, 2014

[2] Asha Philip and Ashok Mathew, "Experimental Study on Mechanical Properties of Geopolymer Concrete Using GGBS," IJSR, vol. 5, no. 5, pp. 2465-2468, 2016

[3] ACI Committee, "Fly Ash, Slag, Silica Fume, and Natural Pozzolans in Concrete," presented at the Proceedings of the Third International Conference, U.S.A, 1989, pp. 54-72.

[4] Dr.-Ing. Olaf Aßbrock et al., "Ground Granulated Blast Furnace Slag (GGBS) as a concrete additive - Current situation and scenarios for its use in Germany," The Federal Association of the German ReadyMixed Concrete Industry, German, 2007.

[5] Peter W.C. Leung and H.D. Wong, "Final Report on Durability and Strength Development of Ground Granulated Blast furnace Slag Concrete," Geotechnical engineering office civil engineering and development department the government of the Hong Kong special administrative region, Hong Kong, GEO Special Project Report 258, 2010.

[6] Professor Rafat Siddique, Waste Materials and By-Products in Concrete, vol. 1. Patiala, India: Springer, 2008.

[7] Russell T. Flynn and and Thomas J. Grisinger, "Slag Cement in Concrete and Mortar," American Concrete Institute, ACI 233R-03 233, 2003.

[8] A Y Ilyushechkin, D G Roberts, D French, and D J Harris, "IGCC Solids Disposal and Utilisation, Final Report for ANLEC Project 5 0710-0065," CSIRO, Australia, 2012.

[9] Dr. En Yi Chen, "Application of GGBS in China -A Gradual Shift From Cost-Savings To Durability," presented at the 2nd Global Slag Conference \& Exhibition, Bangkok, Thailand, 2006, pp. 1-10.

[10] Thavasumony D, Thanappan Subash, Sheeba D, "High Strength Concrete using Ground Granulated Blast Furnace Slag (GGBS)," International Journal of Scientific \& Engineering Research, vol. 5, no. 7, pp. 1050-1054, 2014.

[11] ACI Committee 233, "Ground Granulated Blast-Furnace Slag as a Cementitious Constituent in Concrete," ACI, USA, 233, 2000.

[12] S. Arivalagan, "Sustainable Studies on Concrete with GGBS As a Replacement Material in Cement," Jordan Journal of Civil Engineering, vol. 8, no. 3, pp. 263-270, 2014.

[13] Quaid Johar Bhattiwala and Kuldeep Dabhekar, "Effect of Cementitious Waste Material (GGBS) on concrete as a Replacement in Cement," IJSTE, vol. 2, no. 11, 2016.

[14] Bahador Sabet Divsholi*, Tze Yang Darren Lim, and Susanto Teng, "Durability Properties and Microstructure of Ground Granulated Blast Furnace Slag Cement Concrete," International Journal of Concrete Structures and Materials, vol. 8, no. 2, pp. 157-164, 2014.

[15] Sun-Woo Kim,Wan-Shin Park,Young-Il Jang,Song-Hui Yun,HyunDo Yun and Do-Gyum Kim, "The Effect of Mineral Admixture on the Compressive Strength Development of Concrete," Contemporary Engineering Sciences, vol. 8, no. 13, pp. 541-547, 2015.

[16] Vinayak Awasare, and Prof. M. V. Nagendra, "Analysis of Strength Characteristics of GGBS Concrete," Int J Adv Engg Tech, vol. V, no. II, pp. 82-84, 2014

[17] B.Mangamma, Dr N.Victor babu,P.hD, G.Hymavathi, “An Experimental Study on Behavior of Partial Replacement of Cement with Ground Granulated Blast Furnace Slag,” ijera, vol. 6, no. 12, 2016.

[18] Maitri Mapa, Hemalatha T., Rama Chandra, Murthy A. "Investigation on Mechanical Properties of Silica and GGBS Incorporated Cement Mortar," ICISE, vol. 04, no. 13, 2015.

[19] T.D.GunneswaraRao, P.Alfrite, G.Mallikarjuna Rao, Mudimby Andal, "Fracture Parameters of Fly Ash and GGBS Based
Geopolymer Concrete," Trans Tech Publ., vol. 764-765, pp. 1090 1094, 2015.

[20] Zhao Jun, Wang Xinling, Qian Hui and Chu Liusheng, Reinforced Concrete Fundamentals, 1st ed., vol. 1. China: China Architecture and Building Press, 2015.

[21] Yingzi Yang, Maoguang, Hongwei Deng and Qi Liu, "Effects of Temperature on Drying Shrinkage of Concrete," Trans Tech Publ., vol. 584-586, pp. 1176-1181, 2014.

[22] Dongqing Zhang, Xueying Li, Xinwei Ma and Zheng Wang, "Effects of Mineral Admixtures on the Chloride Permeability of Hydraulic Concrete," Trans Tech Publ., vol. 168-170, pp. 2082-2085, 2011.

[23] Nevile. Adam M., Properties of Concrete, 3rd ed. Great Britain: Longman Singapore, 1994.

[24] Ke-Liang LI, Guo-Hong Huang, Lin-Hua Jiang, Yue-Bo Cai, Jian Chen and Jian-Tong Ding, "Study on Abilities of Mineral Admixtures and Geopolymer to Restrain ASR," Trans Tech Publ., vol. 302-303, pp. 248-254, 2006.

[25] Mickael Saillio, Véronique Baroghel-Bouny, and and Sylvain Pradelle, "Effect of Carbonation and Sulphate on Chloride Ingress in Cement Pastes and Concretes with Supplementary Cementitious Materials," Trans Tech Publ., vol. 711, pp. 241-248, 2016.

[26] H. H. Seleem, A. M. Rashad and B. A. El-Sabbagh, "Performance of Blended Cement Concrete Against Seawater Attack," Trans Tech Publ., vol. 64, pp. 19-24, 2010.

First Author Eskinder Desta, $\mathrm{PhD}$ candidate in Civil Engineering, Zhengzhou University, China.

Second Author Professor Zhao Jun, Well known Professor in School of Civil Engineering in Zhengzhou Unversity, China. 